\title{
PHYTOCHEMICAL SCREENING AND CHARACTERIZATION OF VOLATILE COMPOUNDS BY GAS CHROMATOGRAPHY-MASS SPECTROMETRY FROM “NEPHROLEPIS EXALTATA”
}

\author{
DEEPAK KUMAR SHARMA ${ }^{1 *}$, DAVE RS ${ }^{2}$, SHAH KR ${ }^{3}$ \\ ${ }^{1}$ Department of Chemistry, HVHP Institute of Post Graduate Studies and Research, Kadi, Gujarat, India. ${ }^{2}$ Department of Chemistry, Arts, \\ Science and Commerce College, Pilvai, Gujarat, India. ${ }^{3}$ Department of Biotechnology, Pramukh Swami Science and H.D Patel Arts College, \\ Kadi, Gujarat, India. Email: dbsikhwal@gmail.com \\ Received: 18 April 2021, Revised and Accepted: 31 May 2021
}

ABSTRACT

Objective: Plants contain various types of phytochemicals with different solvent as per solvation properties, depending on their polarity. The goal of this analysis is to compare the effects of different solvents on the phytochemical profile and the characterization of different volatile bioactive compounds of Nephrolepis exaltata, a typical fern belonging to pteridophyte species.

Methods: For the screening of phytochemical, a sequential extraction was carried out using different solvent systems namely methanol (MeOH), chloroform, carbon tetrachloride, hexane, and ethyl acetate (EtAc). A varied range of phytochemicals was found in the extracts. The volatile components were analyzed using the hyphenated technique gas chromatography-mass spectrometry (GC-MS).

Results: All the extracts were found to be rich in alkaloids, whereas phenols and Phytosterols were extracted only in MeOH. The MeOH extract of the fern presented positive results for six phytochemical tests and the n-Hexane $(\mathrm{nH})$ extract presented positive results for seven phytochemical tests. The present investigation on the plant $N$. exaltata aimed to prove that pteridophytes should have various kinds of bioactive phytochemicals and the selection of solvent for extraction of phytochemicals should be based on the target compounds.

Conclusion: From the \% yield of different extract, it can be concluded that some the bioactive phytochemicals are more soluble in more polar solvents such as $\mathrm{MeOH}$, some are soluble in moderate solvents like EtAc and mostly non-polar organic molecules can be extracted using non-polar solvents like $\mathrm{nH}$. The GC-MS characterization indicates the presence of different fatty compounds and sterols in the plant extract.

Keywords: Nephrolepis exaltata, Phytochemical screening, Squalene, Astaxanthin, Gas chromatography-mass spectrometry.

(C) 2021 The Authors. Published by Innovare Academic Sciences Pvt Ltd. This is an open access article under the CC BY license (http://creativecommons.org/ licenses/by/4.0/) DOI: http://dx.doi.org/10.22159/ajpcr.2021v14i7.41869. Journal homepage: https://innovareacademics.in/journals/index.php/ajpcr

\section{INTRODUCTION}

Plants are of greatsignificance to the welfare of humans and communities. There are many highly diversified bioactive compounds and many of them have restorative properties and interesting biological activity. Medicinal plants tend to be high in secondary metabolites, which are commonly used in herbal medicine to fight and treat different diseases; these metabolites are commonly vocalized as "Phytochemical" [1]. Natural products including plant extract which might be pure or taken as a standardized extract provide endless possibilities for new drug discoveries due to the unparalleled abundance of chemical variety. Due to the heterogeneous nature of plants; standardization of natural products is a complicated activity [2].

Pteridophytes (ferns and fern allies) are known as a reptile community of plants and are one of the main groups of vascular plants. The uses of Nephrolepis (A typical genus of Pteridophytes) are not well understood by most antiquated people, as they are not simply available as flowering plants; that is why, except for a few reports, there is no information available on medically relevant literature. Many species of Nephrolepis, that is, Nephrolepis cordifolia were reported to have antibacterial, antitussive, styptic, and antifungal, and can be used in coughs, wounds [3]. Nephrolepis exaltata was reported to have bioactive constituents which can be used against women's sterility for a month and is also used in the treatment of menstrual disorders and Birth-aid in parturition [4].

Numerous varieties of plants are remarkably suited for life throughout hot, desert areas where the water supply remains exceedingly low and species must deal with the long droughts. Such resilience strengths seem to be the product of numerous bioactive metabolites. Plant species have been identified in the health industry due to their large variety of cognitive variability and the diverse variety of phytochemical constituents. The massive quantities of these phytochemicals, which may defend prevent damage caused by free radicals, accumulate in different parts of the plant [5].

To research for the identification of various secondary metabolites in $N$. exaltata extracts, namely, flavonoids, saponins, tannins, alkaloids, anthracene derivatives, sterols, and terpenes, phytochemical screening was performed based on a set of staining precipitation reactions. The gas chromatography-mass spectrometry (GC-MS) is a significant analytical framework for the characterization of volatile naturally occurring substances in plant organisms. Therefore, the objective of this study was to carry out a comparative investigation on the chemical composition of N. exaltata by phytochemical screening and GC/MS analysis.

\section{METHODS}

\section{Collection of plant materials}

The fresh plants were collected from a local surrounding in Kadi $\left(23.2973^{\circ} \mathrm{N}, 72.3302^{\circ} \mathrm{E}\right)$ during December 2019. Identification and authentication of the plant parts were done by Dr. K.J Bhatt at the Department of Biology, Pramukh Swami Science and H.D Patel Arts College, Kadi.

\section{Processing of plant materials}

Leaves and stems of the selected plant species were thoroughly washed with distilled water and were air-dried at $28-40^{\circ} \mathrm{C}$ for 30 days. The dried material was powdered in an electric grinder. This was done to increase the surface area of the sample for improved solvent penetration of cells 
and enhanced extraction of secondary metabolites. The plant material was stored in airtight vessel for further analysis.

\section{Choice of solvents}

Effective determination of biologically active compounds from plant material depends primarily on the form of solvent used in the extraction method. Agood solvent for extracting the bioactive metabolites from plants includes low toxicity, ease of evaporation at low heat, encouragement of fast physiological absorption of the extract, preservative activity, and inability to make the extract complex or dissociate. The considerations influencing the choice of solvent are the number of phytochemicals to be extracted, the rate of extraction, the variety of different compounds extracted, the diversity of inhibitory compounds extracted, the ease of subsequent treatment of the extracts, the toxicity of the solvent in the bioassay process, and the possible health threat of the extractants [6].

Due to the presence of polyphenols in methanolic extract; it is most widely used relative to aqueous extract. Alcohols are more effective in penetration of cell walls and seed degradation, which have a unipolar character and allow polyphenols to be extracted from cells [7] whereas ether is commonly used selectively for the extraction of coumarins and fatty acids. Occasionally, tannins and terpenoids are found in the aqueous phase but are more often obtained by treatment with less polar solvents like chloroform.

n-Hexane $(\mathrm{nH})$ is a poorer solvent for flavonoids recovery among the plant extracts compared to those more polar solvents but non-polar alkaloids can be found by treating the sample with $\mathrm{nH}$ [8].

\section{Extraction procedures for phytochemical screening}

A thimble with a dry sample was prepared with $10 \mathrm{~g}$ of the sample. The extraction was done using Soxhlet extractor with Methanol $(\mathrm{MeOH}), \mathrm{nH}$, Chloroform, Carbon tetrachloride, and ethyl acetate (EtAc) as solvent. The thimble was placed into a thimble holder and the holder was clipped. Then after a sufficient amount (one glass reclaiming tube full - approximately $40 \mathrm{ml}$ ) of solvent was poured into round bottom flask (RBF) of Soxhlet apparatus, so the plant material in the thimble could be extracted. The RBF was coupled to the extractor with the ring clamp tightly adjusted. The temperature was set to $40^{\circ} \mathrm{C}$ in the heating element. The heater switch, the main power switch, and the condenser water were turned on. As the solvents were boiled, glassware was inspected for leaks so as to ensure that there were no volumetric losses. Extraction was carried out using standard methods for $16 \mathrm{~h}$ at Low setting (condensation rate of 2-3 drops/s). After extraction, the temperature of the heating element was lowered down by shutting down the power and water supply and allowed the solvent to drain out of the thimbles (about $30 \mathrm{~min}$ )

\section{Phytochemical screening}

Phytochemical examinations were carried out for all the extracts as per the standard methods.

\section{Detection of alkaloids}

Extracts were dissolved individually in dilute hydrochloric acid and filtered.

\section{Mayer's test}

Filtrates were treated with Mayer's reagent (Potassium Mercuric Iodide). The formation of a yellow-colored precipitate indicates the presence of alkaloids.

\section{Wagner's test}

Filtrates were treated with Wagner's reagent (Iodine in Potassium Iodide). The formation of brown/reddish precipitate indicates the presence of alkaloids.

Dragendroff's test

Filtrates were treated with Dragendroff's reagent (solution of Potassium Bismuth Iodide). The formation of a red precipitate indicates the presence of alkaloids.
Detection of carbohydrates

Extracts were dissolved individually in $5 \mathrm{ml}$ distilled water and filtered. The filtrates were used to test for the presence of carbohydrates.

Molisch's test

Filtrates were treated with two drops of alcoholic $\alpha$-naphthol solution in a test tube. The formation of the violet ring at the junction indicates the presence of carbohydrates.

Benedict's test

Filtrates were treated with Benedict's reagent and heated gently. Orange-red precipitate indicates the presence of reducing sugars.

Fehling's test

Filtrates were hydrolyzed with dil $\mathrm{HCl}$, neutralized with alkali and heated with Fehling's A and B solutions. The formation of a red precipitate indicates the presence of reducing sugars.

\section{Detection of glycosides}

Extracts were hydrolyzed with dil $\mathrm{HCl}$, and then subjected to test for glycosides.

Modified Borntrager's test

Extracts were treated with Ferric Chloride solution and immersed in boiling water for about $5 \mathrm{~min}$. The mixture was cooled and extracted with equal volumes of benzene. The benzene layer was separated and treated with ammonia solution. The formation of rose-pink color in the ammonical layer indicates the presence of anthranilic glycosides.

Legal's test

Extracts were treated with sodium nitroprusside in pyridine and sodium hydroxide. The formation of pink to blood-red color indicates the presence of cardiac glycosides.

\section{Detection of saponins}

Froth test

Extracts were diluted with distilled water to $20 \mathrm{ml}$ and this was shaken in a graduated cylinder for $15 \mathrm{~min}$. The formation of a $1 \mathrm{~cm}$ layer of foam indicates the presence of saponins.

Foam test

$0.5 \mathrm{~g}$ of extract was shaken with $2 \mathrm{ml}$ of water. If foam produced persists for $10 \mathrm{~min}$, it indicates the presence of saponins.

\section{Detection of phytosterols}

Salkowski's test

Extracts were treated with chloroform and filtered. The filtrates were treated with few drops of Conc. sulfuric acid, shaken and allowed to stand. The appearance of the golden yellow color indicates the presence of triterpenes.

\section{Liebermann-Burchard's test}

Extracts were treated with chloroform and filtered. The filtrates were treated with few drops of acetic anhydride, boiled, and cooled. Conc. sulfuric acid was added. The formation of a brown ring at the junction indicates the presence of phytosterols.

\section{Detection of phenols}

Ferric Chloride Test: Extracts were treated with 3-4 drops of ferric chloride solution. The formation of bluish-black color indicates the presence of phenols.

Detection of tannins

Gelatin test

To the extract, $1 \%$ gelatin solution containing sodium chloride was added. The formation of a white precipitate indicates the presence of tannins. 
Detection of flavonoids

Alkaline reagent test

Extracts were treated with few drops of sodium hydroxide solution. Formation of intense yellow color, which becomes colorless on the addition of dilute acid, indicates the presence of flavonoids.

Lead acetate test

Extracts were treated with few drops of lead acetate solution. The formation of a yellow color precipitate indicates the presence of flavonoids.

\section{Detection of proteins and amino acids}

Xanthoproteic test

The extracts were treated with few drops of conc. nitric acid. The formation of a yellow color indicates the presence of proteins.

Ninhydrin test

To the extract, $0.25 \% \mathrm{w} / \mathrm{v}$ ninhydrin reagent was added and boiled for few minutes. The formation of blue color indicates the presence of amino acid.

Table 1: \% Yields of $N$. exaltata leaves and stem in different solvent

\begin{tabular}{lll}
\hline Solvent & \% Yield & \\
\cline { 2 - 3 } & Leaves & Stem \\
\hline $\mathrm{MeOH}$ & 6.97 & 4.89 \\
$\mathrm{EtAc}$ & 8.41 & 1.47 \\
$\mathrm{nH}$ & 5.67 & 4.29 \\
Chloroform & 3.52 & 2.92 \\
Carbon Tetrachloride & 3.57 & 2.21 \\
\hline
\end{tabular}

N. exaltata: Nephrolepis exaltata, MeOH: Methanol, EtAc: Ethyl acetate, nH: n-Hexane

\section{Characterization of compounds by GC-MS}

The GC-MS study of the leaf and stem extracts of $N$. exaltata was conducted using complex and multidimensional gas chromatography coupled with a GS-MS. For the characterization study, a mixture of three solvents was prepared in the ratio 1:1:1, v/v/v: EtAc: hexane:MeOH. The solvent system was used for the extraction of bioactive compounds from dry plants. For the concentrated extraction, $10 \mathrm{~g}$ of the sample were extracted with $30 \mathrm{ml}$ of a solvent mixture using cold extraction for $24 \mathrm{~h}$ with constant stirring. GC was performed using a Perkin Elmer Clarus 680/SQ8C with Elite-5MS C18 column (30 m $\times 0.25 \mathrm{~mm}$ i.d., $0.25 \mu \mathrm{m}$ ) (Perkin Elmer N9316282 GC System, Sr. No.-1277168, USA). For Leaf extract of $N$. exaltata, the experiment time was set 46:00 min, the sampling rate was set $1.56250 \mathrm{pts} / \mathrm{s}$, and the oven temperature was set $70^{\circ} \mathrm{C}$ for $2.00 \mathrm{~min}$ (Ramp $1: 10.0^{\circ} \mathrm{C} / \mathrm{min}$ to $150^{\circ}$, hold for $5.00 \mathrm{~min}$ and Ramp 2: $5.0^{\circ} \mathrm{C} / \mathrm{min}$ to $280^{\circ}$, and hold for $5.00 \mathrm{~min}$ ). For the stem extract of N. exaltata, the experiment time was set 60:00 min, the sampling rate was set $1.56250 \mathrm{pts} / \mathrm{s}$ and the oven temperature was set $70^{\circ} \mathrm{C}$ for $2.00 \mathrm{~min}$ (Ramp 1: $10.0^{\circ} \mathrm{C} / \mathrm{min}$ to $150^{\circ}$, hold for $10.00 \mathrm{~min}$ and Ramp $2: 5.0^{\circ} \mathrm{C} / \mathrm{min}$ to $300^{\circ}$, and hold for $10.00 \mathrm{~min}$ ). The extracted $1.0 \mu \mathrm{L}$ sample for every run was injected manually and in the splitless mode. The identification of the various components was based on a comparison of their mass spectra with those of mainlib, replib, nist_msms, FAMES2011, and MPW2011 Library mass Spectra database and mass spectra from the literature.

\section{RESULTS}

\section{$\%$ yield of the extracts}

Different solvents based on polarity and solvation property were used for the extraction. It was observed that the highest percentage yield of extract was found in $\mathrm{MeOH}$ and EtAc for Leaves. The \%Yield is expressed in Table 1.

Phytochemical analysis of the extracts

A qualitative study of different extracts of $N$. exaltata showed positive results for several phytochemical samples. The results obtained

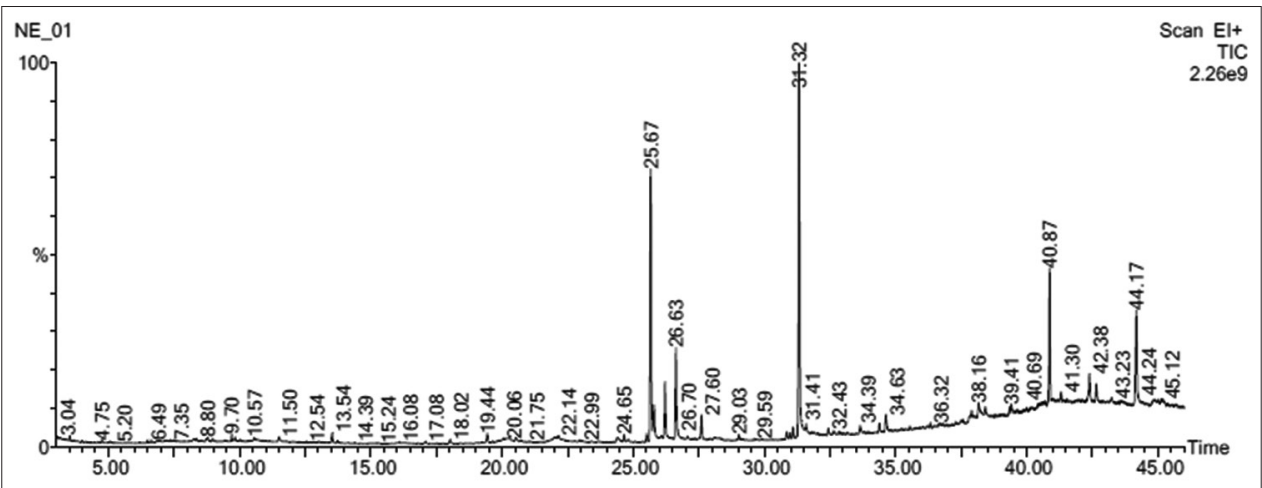

Fig. 1: Gas chromatography-mass spectrometry report of Nephrolepis exaltata leaves

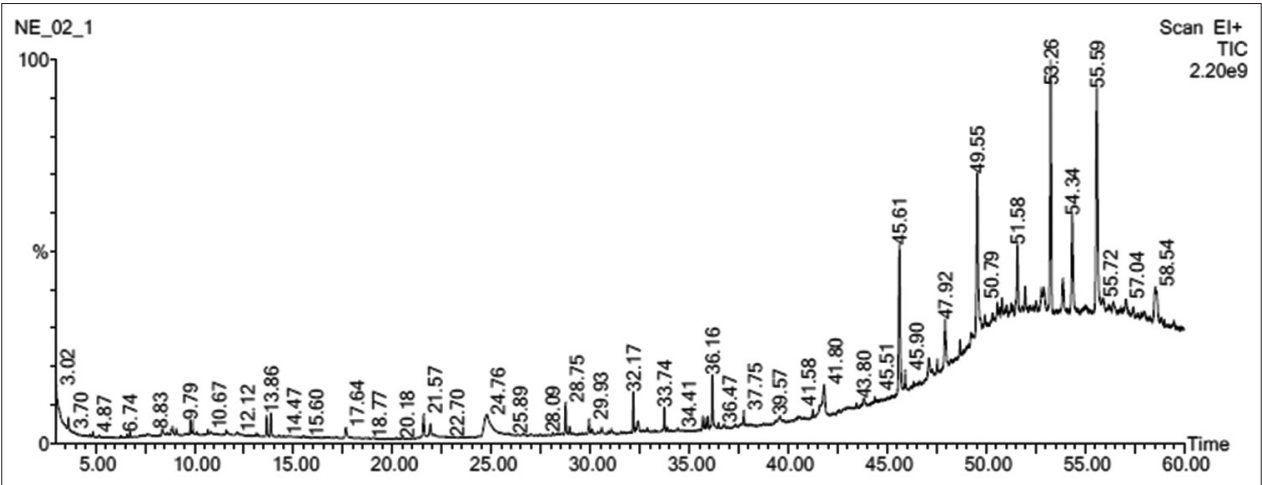

Fig. 2: Gas chromatography-mass spectrometry report of Nephrolepis exaltata stem 
for the qualitative screening of phytochemicals in the extracts are presented in Table 2. In this study among all solvent extractions, abundance of phytochemicals was found high in the methanolic extract. Remarkably carbohydrates, saponins, and phenols are absent in most the extract. Phyto constituents of both plants are almost similar and the probabilities of finding bioactive compounds in several solvents are depend on the solubility of components. The polarity of solvents plays a major role in extracting the phytochemicals.

\section{Characterization of compounds by GC-MS}

The GC-MS analysis of $N$. exaltata leaves and stem is shown in Figs. 1 and 2, respectively. On the basis of temperature gradient GC system,

Table 2: Phytochemical screening of $N$. exaltata in different solvent

\begin{tabular}{|c|c|c|c|c|c|c|c|c|c|c|}
\hline \multirow[t]{2}{*}{ Phytochemicals } & \multicolumn{2}{|l|}{$\mathrm{MeOH}$} & \multicolumn{2}{|l|}{ EtAc } & \multicolumn{2}{|l|}{ nH } & \multicolumn{2}{|c|}{ Chloroform } & \multicolumn{2}{|c|}{$\begin{array}{l}\text { Carbon } \\
\text { tetrachloride }\end{array}$} \\
\hline & $\begin{array}{l}\text { Leaf } \\
\text { extract }\end{array}$ & $\begin{array}{l}\text { Stem } \\
\text { extract }\end{array}$ & $\begin{array}{l}\text { Leaf } \\
\text { extract }\end{array}$ & $\begin{array}{l}\text { Stem } \\
\text { extract }\end{array}$ & $\begin{array}{l}\text { Leaf } \\
\text { extract }\end{array}$ & $\begin{array}{l}\text { Stem } \\
\text { extract }\end{array}$ & $\begin{array}{l}\text { Leaf } \\
\text { extract }\end{array}$ & $\begin{array}{l}\text { Stem } \\
\text { extract }\end{array}$ & $\begin{array}{l}\text { Leaf } \\
\text { extract }\end{array}$ & $\begin{array}{l}\text { Stem } \\
\text { extract }\end{array}$ \\
\hline \multicolumn{11}{|l|}{ Alkaloids } \\
\hline Mayer's test & ++ & ++ & + & ++ & ++ & ++ & ++ & ++ & ++ & ++ \\
\hline Wagner's test & ++ & ++ & + & ++ & ++ & ++ & ++ & ++ & ++ & ++ \\
\hline Dragendroff's test & ++ & + & + & + & + & + & ++ & + & ++ & + \\
\hline \multicolumn{11}{|l|}{ Carbohydrate } \\
\hline Molisch's test & - & - & + & - & - & - & - & + & - & - \\
\hline Benedict's test & - & - & + & - & - & - & - & - & - & - \\
\hline Fehling's test & - & - & + & - & - & - & - & - & - & - \\
\hline \multicolumn{11}{|l|}{ Glycosides } \\
\hline Modified borntrager's test & ++ & ++ & ++ & ++ & ++ & + & ++ & ++ & ++ & + \\
\hline Legal's test & ++ & ++ & ++ & ++ & ++ & - & ++ & ++ & ++ & - \\
\hline \multicolumn{11}{|l|}{ Saponins } \\
\hline \multicolumn{11}{|l|}{ Phytosterols } \\
\hline Salkowski's test & ++ & + & - & - & - & + & - & - & - & + \\
\hline Liebermann-burchard's test & ++ & - & - & - & - & - & + & - & + & - \\
\hline \multicolumn{11}{|l|}{ Phenol } \\
\hline Ferric chloride test & + & + & + & - & - & - & - & - & - & - \\
\hline \multicolumn{11}{|l|}{ Tannins } \\
\hline Gelatin solution $\mathrm{NaCl}$ test & - & ++ & - & ++ & ++ & ++ & ++ & ++ & ++ & ++ \\
\hline \multicolumn{11}{|l|}{ Flavonoids } \\
\hline Alkaline reagent test & ++ & ++ & ++ & ++ & ++ & ++ & ++ & ++ & ++ & ++ \\
\hline Lead acetate test & ++ & ++ & ++ & ++ & ++ & ++ & ++ & ++ & ++ & ++ \\
\hline \multicolumn{11}{|l|}{ Proteins } \\
\hline Xanthoproteic test & + & + & + & + & - & - & - & - & - & - \\
\hline Ninhydrin test & + & - & + & - & - & - & - & - & + & - \\
\hline
\end{tabular}

*Here- (++) indicates high presence, (+) presence in trace amount and (-) indicates absence of elements, MeOH: Methanol, EtAc: Ethyl acetate, nH: $\mathrm{n}-\mathrm{Hexane}$

N. exaltata: Nephrolepis exaltata

Table 3: GC-MS chemical constituents of $N$. exaltata leaves

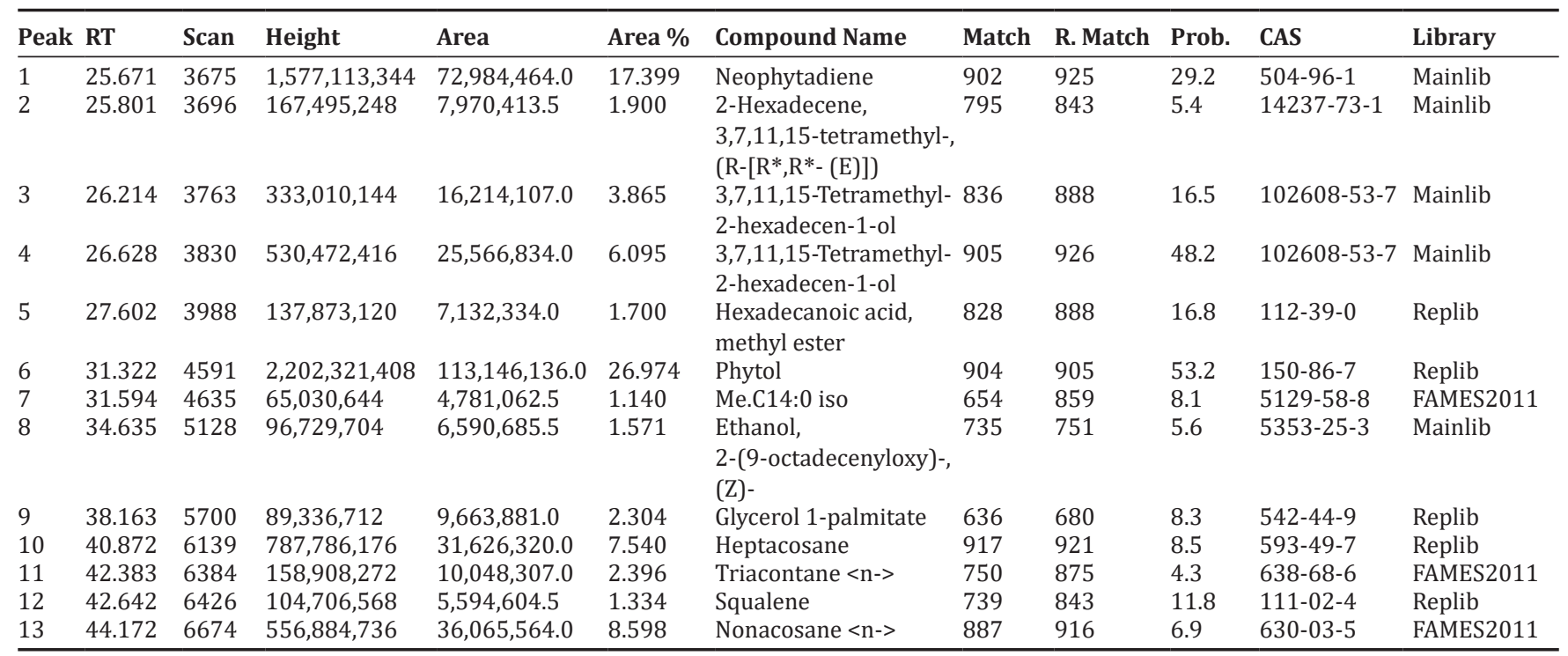

*RT: Retention time, Prob.: Probability Time, CAS: Chemical abstract service, GC-MS: Gas chromatography-mass spectrometry,

N. exaltata: Nephrolepis exaltata 
the analysis was carried out which indicating high concentration of secondary metabolites.

\section{DISCUSSION}

This study provides a guide to the extraction, phytochemical screening, and GC-MS characterization of the $N$. exaltata stem as well as leave portion. The percentage yield for the different extracts from leaves and stem is given in Table 1 which shows the solvent efficiency in extracting secondary metabolites. Methanolic and EtAc extract yield was found too high in both plants, while the phytochemical screening in Table 2 shows the presence of secondary metabolites such as saponins, tannins, steroids, alkaloids, and phenols. In combination with the mass spectrum of plant extracts, gas chromatography was analyzed to understand the various secondary metabolites together with their molecular weight and molecular formula. GC-MS is a versatile hyphenated instrument

Table 4: GC-MS chemical constituents of $N$. exaltata stem

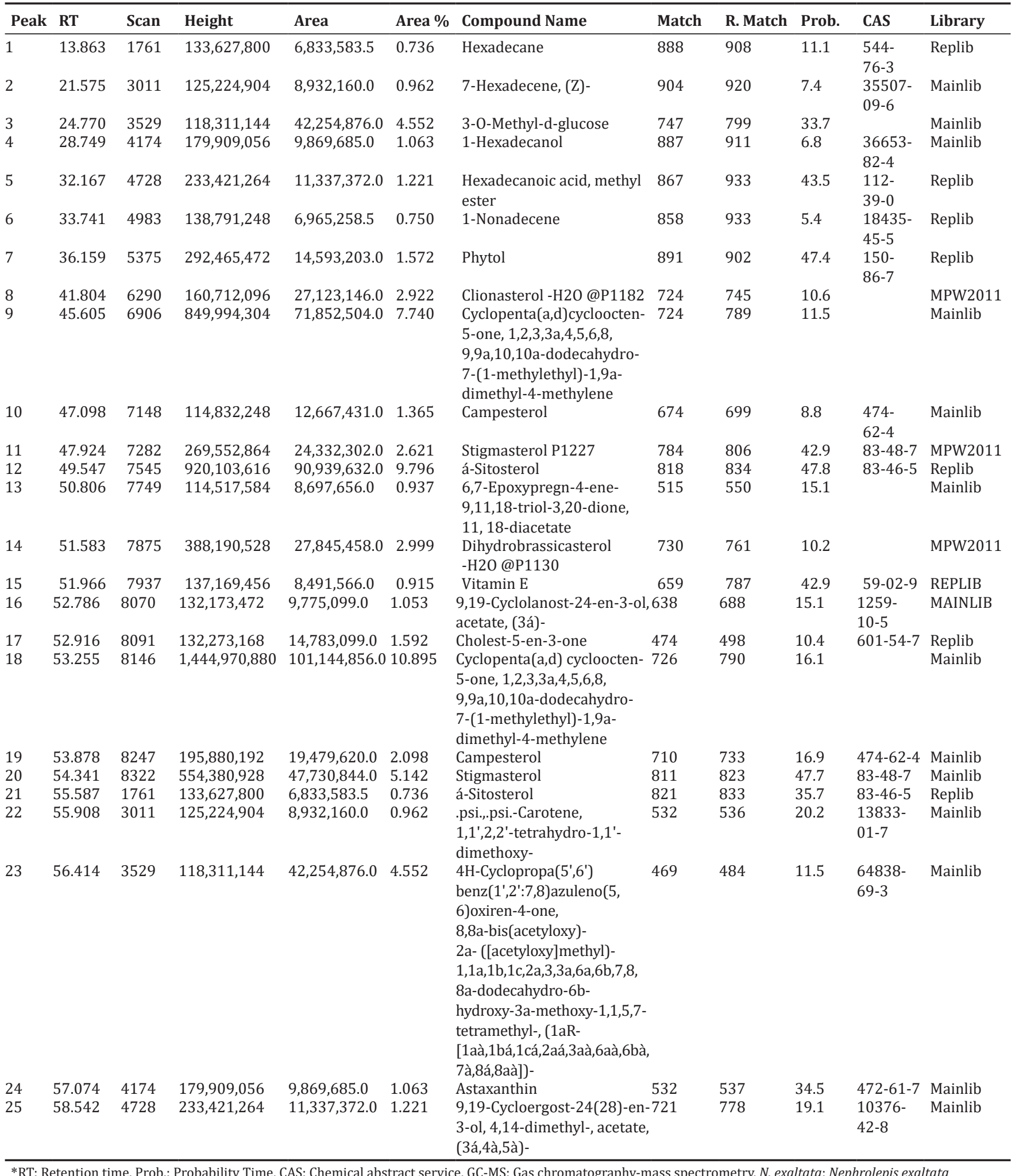


for distinguishing a band of secondary metabolites depending on the molecular mass into some kind of single compound. GC-MS report in Figs. 1 and 2 shows different peaks at various retention time (RT). Phytol is present in both extracts predominantly whereas Vitamin E and (+)-à-Tocopherol were reported to stem of Nephrolepis. Both plant extracts were found to be rich in steroidal components, that is, Campesterol, Stigmasterol, á-Sitosterol, and Clionasterol $-\mathrm{H}_{2} \mathrm{O}$. They were shown to have pharmacological behaviors some of which may make a significant contribution to the plant's healing ability.

From the interpretation of GC-MS data for the leaf extract in Table 3, total 13 components were identified whereas, 25 components were identified for stem extract showing in Table 4. The most abundant component by peak area in $N$. exaltata Leaf extract was shown to be phytol $26.974 \%$ at RT 31.322 followed by Neophytadiene. Among the separating compounds, Neophytadiene was identified at RT 25.671 with 29.2 probability which was reported to be antibacterial [9] and anti-inflammatory actives [10]. At RT 26.628 with 48.2 probability 3,7,11,15-Tetramethyl-2-hexadecen-1-ol was identified which have antibacterial and anti-inflammatory activities [11]. The antioxidant and antinociceptive properties of "Phytol" have been proven [12]. Glycerol1-palmitate an antiviral [13] and an Antihypertensive, Vasodilator monoterpenoid component Nonacosane [14] were also reported at RT 38.163 and 44.172, respectively. A 27-carbon volatile oil component Heptacosane and 30 carbon hydrocarbon Triacontane were also reported in leave extract. "Squalene" was confirmed to be present at RT 42.642 with 11.8 probability in the plant which was reported as an antioxidant by Psomiadou and Tsimidou in olive oil [15]. Besides these compounds Me.C14:0 iso, Hexadecanoic acid, methyl ester, and 2-Hexadecene, 3,7,11,15-tetramethyl-, (R-[R*, $\mathrm{R}^{*}$-(E)])- were also confirmed. The first active compound Hexadecane was identified in less RT (13.863) (0.736\%), and the last compound 9, 19-Cycloergost24(28)-en-3-ol, 4,14-dimethyl-, and acetate, (3á,4à,5à)- was identified in much longest RT (58.542) and high percentage peak area (3.814) was observed in stem extract of $N$. exaltata. Among these 25 compounds, most the phytochemicals belong to steroids and having different biological activities. Dihydrobrassicasterol- $\mathrm{H}_{2} \mathrm{O}$, Clionasterol, Campesterol, Stigmasterol, and á-Sitosterol are steroid compounds that possess several medicinal properties. Vitamin E was also be reported at RT 51.966 with 42.9 probability. In addition, Astaxanthin, an important secondary metabolite was also reported which was reported as an antiwrinkle, inhibitor of UV-induced immunosuppression, and effectively suppresses cell damage [16].

\section{CONCLUSION}

$N$. exaltata is an ornament plant used by people as a decorative shrub; however, the detailed phytochemical analysis of the plant is not recorded. The significant biological components presented in our selected plants were documented by comparative phytochemical screening and GC-MS analysis. Phytochemicals are rich in plants and might be used to treat and cure different diseases. Provisional information about phytochemicals existing in both plant extracts has been established by the current investigation which might be useful for the human population. Although, stem extract was found to be more potent than leaf extract of typical fern $N$. exaltata. The secondary metabolites such as alkaloids, flavonoids, tannins, phytosterols, and glycosides were reported more in methanolic and EtAc extract than other solvents followed by $\mathrm{nH}$. The GC-MS analysis concludes the remarkable presence of essential oils and steroidal compounds in stem extract in comparison with leaf extract of $N$. exaltata which can be the main reason behind the sustainability of plant in semi-dry conditions. Further investigations are needed to stabilize the correlation between the semi-desert characters of plants, their sustainability, and medicinal uses which might be useful for pharmacological evaluation.

\section{ACKNOWLEDGMENTS}

The authors would like to express their gratitude to Gujarat Biotechnology Research Center, Gandhinagar, and Ms. Mittal Nakrani for providing sharing Lab services to carry GC-MS analysis. We also want to acknowledge Pramukh Swami Science and H.D. Patel Arts College and HVHP Institute of Post Graduate Studies and Research to provide laboratory.

\section{AUTHORS CONTRIBUTION}

This work was carried out in collaboration among all authors. Author Deepak Kumar Sharma designed the study, performed the statistical analysis, wrote the protocol, and wrote the first draft of the manuscript. Authors Dr. R.S. Dave and Dr. K.R. Shah managed the analyses of the study and the literature searches. All authors read and approved the final manuscript.

\section{CONFLICT OF INTEREST}

All authors state there are no conflicts of interest about this publication.

\section{FUNDING}

This research did not receive any specific grant from funding agencies in the public, commercial, or not-for-profit sectors.

\section{REFERENCES}

1. Sharma DK, Dave RS, Shah KR. Phytochemicals: Promising potential uses in pharmacology. In: Recent Trends in Pharmaceutical Sciences. India: JPS Scientific Publications; 2019. p. 84-105.

2. Cos P, Vlietinck AJ, Berghea DV, Maes L. Anti-infective potential of natural products: How to developa stronger in vitro proof-of-concept. J Ethnopharmacol 2006;106:290-302

3. Manickam VS, Benjamin A. Medicinal pteridophytes from the Western Ghats. Indian J Tradit Knowl 2007;6:611-8.

4. Singh S, Singh R. Ethnomedicinal use of pteridophytes in reproductive health of tribal women of Pachmarhi biosphere reserve, Madhya Pradesh, India. Int J Pharm 2012;3:4780-90.

5. Suffredini IB, Sader HS, Gonçalves AG, Reis AO, Gales AC, Varella $\mathrm{AD}$, et al. Screening of antibacterial extracts from plants native to the Brazilian Amazon rain forest and atlantic forest. Braz J Med Biol Res 2004;37:379-84.

6. Eloff JN. Which extractant should be used for the screening and isolation of antimicrobial components from plants? J Ethnopharmacol 1998;60:1-8

7. Dai J, Mumper RJ. Plant phenolics: Extraction, analysis and their antioxidant and anticancer properties. Molecules 2010;15:7313-52.

8. Jan S, Khan MR, Rashid U, Bokhari J. Assessment of antioxidant potential, total phenolics and flavonoids of different solvent fractions of monotheca buxifolia fruit. Osong Public Health Res Perspect 2013;4:246-54.

9. Singh R, Dar SA, Sharma P. Antibacterial activity and toxicological evaluation of semi purified hexane extract of Urtica dioica leaves. Res J Med Plant 2012;6:123-35.

10. Adnan M, Chy NU, Kamal AT. Investigation of the biological activities and characterization of bioactive constituents of Ophiorrhiza rugosa var. Prostrata (D.Don) and Mondal leaves through in vivo, in vitro, and in silico approaches. Molecules 2019;24:1367.

11. Nithya M, Ragavendran C, Natarajan D. Antibacterial and free radical scavenging activity of a medicinal plant Solanum xanthocarpum. Int J Food Prop 2018;21:313-27.

12. Santos CC, Salvadori MS, Mota VG, Costa LM, de Almeida AA, de Oliveira GA, et al. Antinociceptive and antioxidant activities of phytol in vivo and in vitro models. Neurosci J 2013;2013:1-9.

13. Sharmila M, Rajeswari M, Jayashree I, Geetha DH. GC-MS analysis of bioactive compounds of Amarantus polygonoides linn. (Amaranthaceae). Int J Appl Adv Sci Res 2016;1:174-80.

14. Paulsamy S, Mallikadevi T, Jamuna S, Karthika K. Analysis for phytoceuticals and bioinformatics approach for the evaluation of therapetic properties of whole plant methanolic extract of Mukia maderaspatana (L.) M. Roem. (Cucurbitaceae)-a traditional medicinal plant in western districts of Tamil Nadu, India. Asian J Pharm Clin Res 2012;5:163-8

15. Psomiadou E, Tsimidou M. On the role of squalene in olive oil stability. J Agric Food Chem 1999;47:4025-32.

16. Davinelli S, Nielsen ME, Scapagnini G. Astaxanthin in skin health, repair, and disease: A comprehensive review. Nutrients 2018;10:522. 